\title{
Comparison between IRI-2012 and GPS-TEC observations over the western Black Sea
}

\author{
Samed Inyurt ${ }^{1}$, Omer Yildirim ${ }^{2}$, and Cetin Mekik ${ }^{1}$ \\ ${ }^{1}$ Geomatics Engineering Department, Bulent Ecevit University, Zonguldak, Turkey \\ ${ }^{2}$ Geomatics Engineering Department, Gaziosmanpasa University, Tokat, Turkey \\ Correspondence to: Samed Inyurt (samed_inyurt@hotmail.com)
}

Received: 2 December 2016 - Revised: 1 May 2017 - Accepted: 20 June 2017 - Published: 14 July 2017

\begin{abstract}
The ionosphere is a dynamic layer which generally changes according to radiation emitted by the sun, the movement of the earth around the sun, and sunspot activity. Variations can generally be categorized as regular or irregular variations. Both types of variation have a huge effect on radio wave propagation. In this study, we have focused on the seasonal variation effect, which is one of the regular forms of variation in terms of the ionosphere.

We examined the seasonal variation over the ZONG station in Turkey for the year 2014. Our analysis results and IRI-2012 present different ideas about ionospheric activity. According to our analysed results, the standard deviation reached a maximum value in April 2014. However, the maximum standard deviation obtained from IRI-2012 was seen in February 2014. Furthermore, it is clear that IRI-2012 underestimated the VTEC values when compared to our results for all the months analysed. The main source of difference between the two models is the IRI-2012 topside ionospheric representation. IRI-2012 VTEC has been produced as a result of the integration of an electron density profile within altitudinal limits of $60-2000 \mathrm{~km}$. In other words, the main problem with regard to the IRI-2012 VTEC representation is not being situated in the plasmaspheric part of the ionosphere. Therefore we propose that the plasmaspheric part should be taken into account to calculate the correct TEC values in midlatitude regions, and we note that IRI-2012 does not supply precise TEC values for use in ionospheric studies.
\end{abstract}

Keywords. Ionosphere (mid-latitude ionosphere; modelling and forecasting)

\section{Introduction}

GPS systems have been used in many scientific studies in recent years. GPS satellites send signals to receivers on L1 and L2 carrier frequencies. The carrier frequencies connecting satellites to receivers are exposed to various factors that can change the GPS signal, which can result in positioning errors. One of the positioning error sources is the ionospheric layer. Since the ionosphere plays an important role in radio communication, ionospheric conditions should be monitored correctly. The total electron content (TEC) is an important parameter that provides information about ionospheric activity. TEC is calculated along the path from the receiver to the satellite in a column with a cross-sectional area of a square metre and is expressed as TECU $10^{16} \mathrm{e} / \mathrm{m}^{2}$ (Chakraborty et al., 2014; Coley et al., 2014; Otsuka et al., 2002; Rama Rao et al., 2006; Schmidt et al., 2008; Spogli et al., 2013; Yildirim et al., 2016).

The ionosphere consists of different layers, such as $D, E$, $F_{1}$, and $F_{2}$, according to the electron density. These layers affect the propagation of radio signals differently. Consequently, understanding the behaviour of each ionospheric layer is of huge importance when it comes to modelling ionospheric errors.

The $D$ layer is the lowermost layer of the ionosphere. It extends from 50 to $90 \mathrm{~km}$. Ionization is less in this layer and disappears at night because of the high recombination of ions. Therefore it is thought that the $D$ layer has little effect on GPS signals (Petrie et al., 2011). The $E$ layer is called the middle layer of the ionosphere and stretches to $150 \mathrm{~km}$. This layer is composed of $E$ and sporadic $E$ layers $\left(E_{\mathrm{S}}\right)$, but ionization occurring in $\left(E_{\mathrm{s}}\right)$ is not related to the $E$ layer. Thus sporadic $E$ can be thought of as separate from the $E$ layer. Ionization results from soft $\mathrm{X}$-ray and ultraviolet solar radia- 


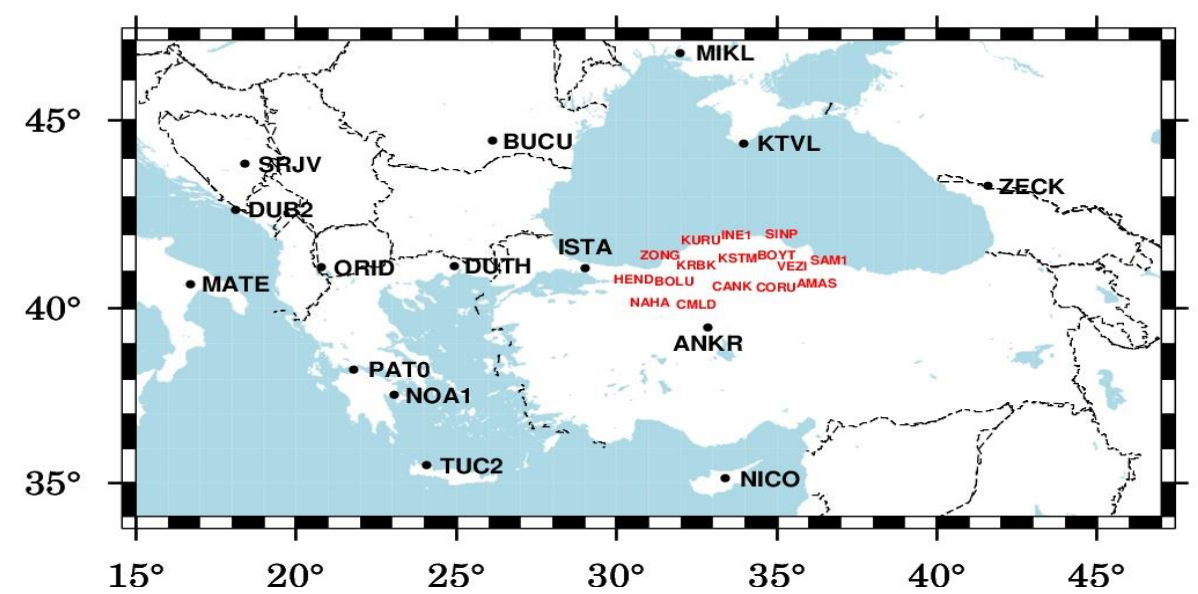

Figure 1. Distribution of stations.

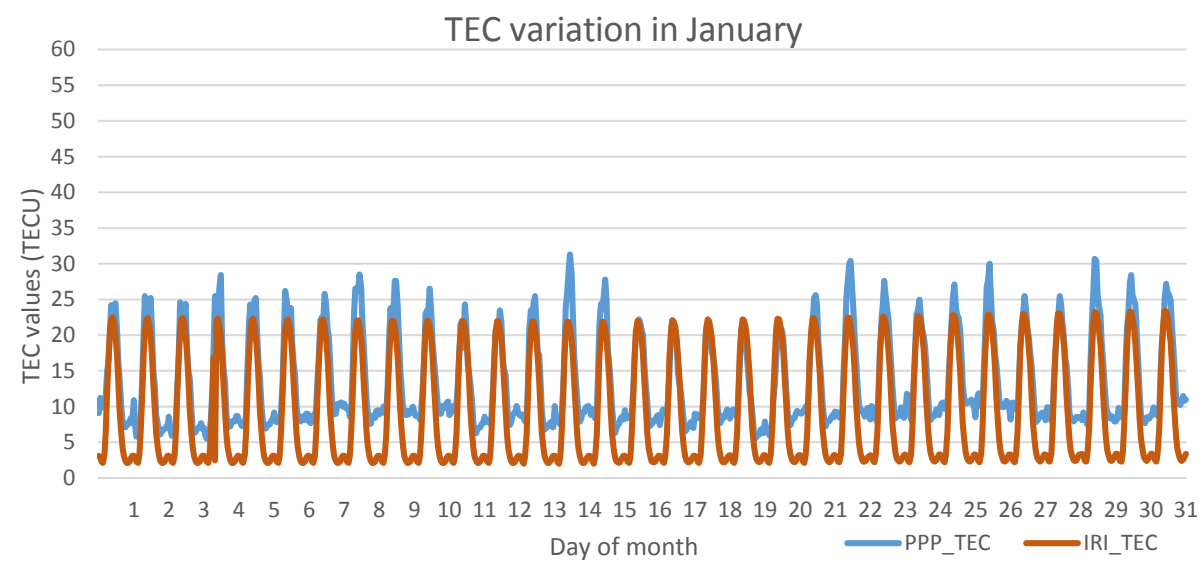

Figure 2. TEC variations in January 2014.

tion in this layer. The $E$ layer becomes extinct at night owing to the recombination of ions, as is the case for the $D$ layer.

The $F$ layer is a major component of the ionosphere in terms of affecting the propagation of radio waves. The $F$ layer includes more free electrons and ions than the other ionospheric layers and consists of two layers $\left(F_{1}\right.$ and $\left.F_{2}\right)$. The $F_{1}$ layer extends from 140 to $210 \mathrm{~km}$ and has a $10 \%$ effect on GPS signals. The $F_{2}$ layer, which extends from 210 to $1000 \mathrm{~km}$, contains most of the free electrons, especially between $250 \mathrm{~km}$ and $450 \mathrm{~km} . F_{2}$ has more ionospheric variability than $F_{1}$. Thus we have focused on the $F_{2}$ layer in order to determine the TEC values in this study.

GPS is essential for increasing satellite-based applications and studies, especially geodetic studies that call for high accuracy. A signal travelling from a satellite to a receiver is affected by many factors that lead to positioning errors. The ionosphere, which is an uppermost layer that extends from 60 to $1000 \mathrm{~km}$, is the most important factor. The ionosphere includes a sufficient number of free electrons and ions and these cause changes in the direction of GPS signals. There- fore TEC, which is needed to calculate ionospheric delay, should be computed for GPS users. TEC is of vital importance for understanding the behaviour of the ionosphere and can be readily determined using GPS dual frequency. However, it is more difficult to filter out ionospheric refraction with a single-frequency receiver.

\section{Methods}

The GPS technique presents an opportunity for use in real time or nearly real time as part of ionosphere services for space weather monitoring. Due to the high popularity of GPS-TEC observations for ionosphere research, including the generation of global and regional ionospheric maps with high temporal and spatial resolution, there is a great demand for a proper model for GPS-TEC specification. As mentioned above, the ionosphere changes in relation to seasonal variations. Therefore, the ionosphere should be described mathematically to allow it to be modelled correctly for GPS singlefrequency users. Pseudorange equations are explained for 


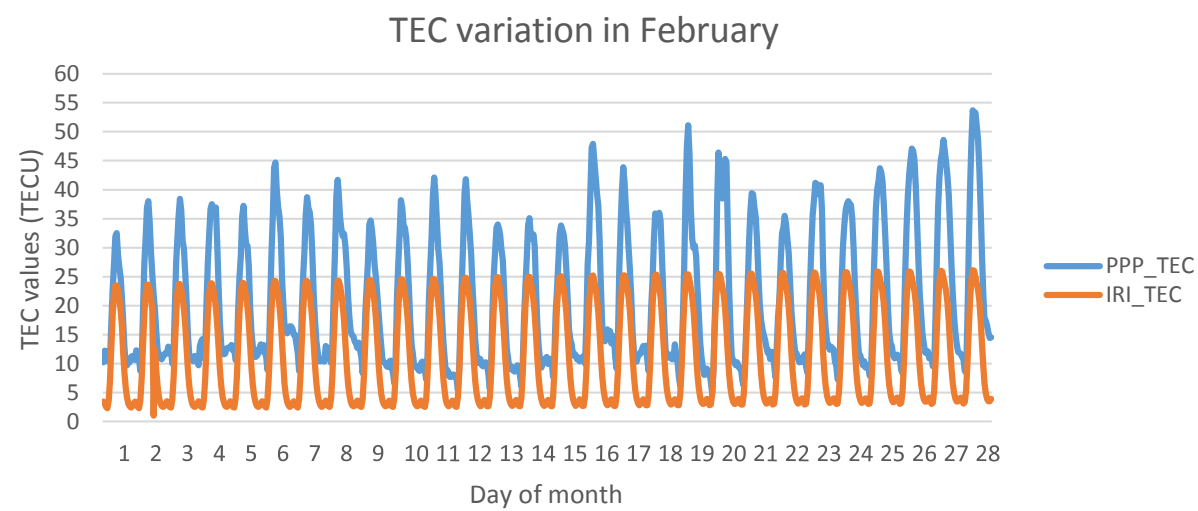

Figure 3. TEC variations in February 2014.

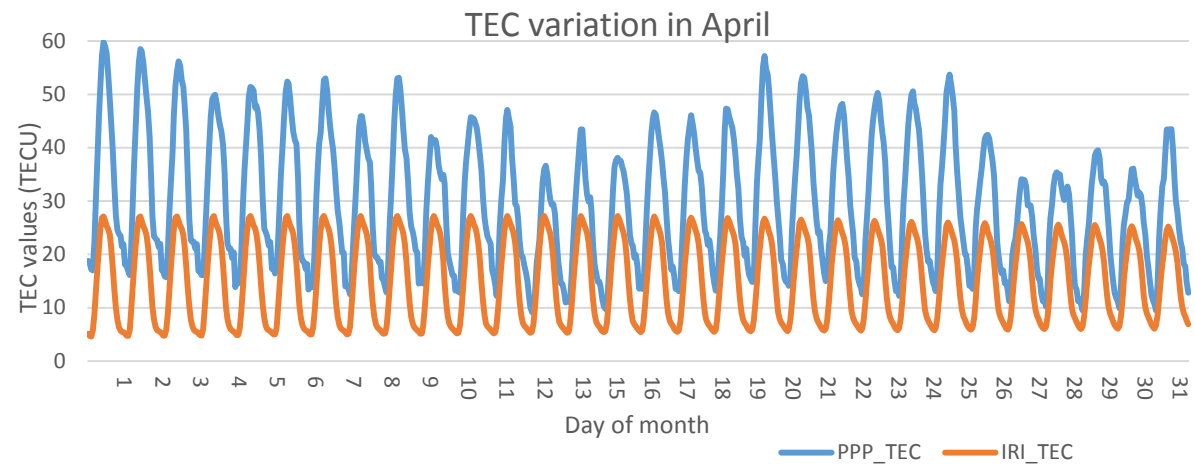

Figure 4. TEC variations in April 2014.

dual-frequency receivers as shown below:

$$
\begin{aligned}
& P_{1, a}^{h}=P_{a}^{h}+c\left(\Delta t^{h}-\Delta t_{a}\right)+I_{1 a}^{h}+T_{a}^{h}+d_{1}^{h}+d_{1, a}+\varepsilon_{p, 1, a}^{h}, \\
& P_{2, a}^{h}=P_{a}^{h}+c\left(\Delta t^{h}-\Delta t_{a}\right)+I_{2 a}^{h}+T_{a}^{h}+d_{2}^{h}+d_{2, a}+\varepsilon_{p, 2, a}^{h},
\end{aligned}
$$

where $\Delta t^{h}$ is satellite clock error, $\Delta t_{a}$ is receiver clock error, $I_{1 a}^{h}$ and $I_{2 a}^{h}$ are ionospheric effects, $T_{a}^{h}$ is tropospheric effect, $c$ is the velocity of light, $d_{1}^{h}$ and $d_{2}^{h}$ represent the code delay for satellite instrument bias, $d_{1, a}$ and $d_{2, a}$ represent the code delay for receiver instrument bias, $\varepsilon_{p, 1, a}^{h}$ and $\varepsilon_{p, 2, a}^{h}$ are random errors, $P_{1, a}^{h}$ and $P_{2, a}^{h}$ are pseudorange measurements, and $P_{a}^{h}$ is the true distance between a receiver and a satellite.
The simple equation for carrier phase measurements can be stated as follows:

$$
\begin{aligned}
\varphi_{1, a}^{h}(t) & =\varphi_{a}^{h}+c\left(\Delta t^{h}-\Delta t_{a}\right)-I_{1 a}^{h}+T_{a}^{h} \\
& -\lambda\left(b_{1, a}^{h}+N_{1, a}^{h}\right)+\varepsilon_{p, 1, a}^{h}, \\
\varphi_{2, a}^{h}(t) & =\varphi_{a}^{h}+c\left(\Delta t^{h}-\Delta t_{a}\right)-I_{2 a}^{h}+T_{a}^{h} \\
& -\lambda\left(b_{2, a}^{h}+N_{2, a}^{h}\right)+\varepsilon_{p, 2, a}^{h},
\end{aligned}
$$

where $\varphi_{1, a}^{h}$ and $\varphi_{2, a}^{h}$ are phase measurements, $\varphi_{a}^{h}$ is the true distance between satellite and receiver, $I_{1 a}^{h}$ and $I_{2 a}^{h}$ are ionospheric effects, $T_{1 a}^{h}$ and $T_{2 a}^{h}$ are tropospheric effects, $b_{1, a}^{h}$ and $b_{2, a}^{h}$ represent the phase advance of the satellite instrument bias, $\varepsilon_{p, 1, a}^{h}$ and $\varepsilon_{p, 2, a}^{h}$ are GPS residuals, $N_{1, a}^{h}$ and $N_{2, a}^{h}$ represent the integer phase ambiguity, and $\lambda$ is the wavelength at frequency.

Code and phase measurements have been affected by the ionosphere. These effects, grouped and referred to here as the delay for code measurement and phase advance for phase measurement, can be explained with geometry-free linear combinations. Dual-frequency GPS receivers save not only the code pseudo-range, but also the phase measurements on L1 and L2 frequencies. 


\section{TEC variation in May}

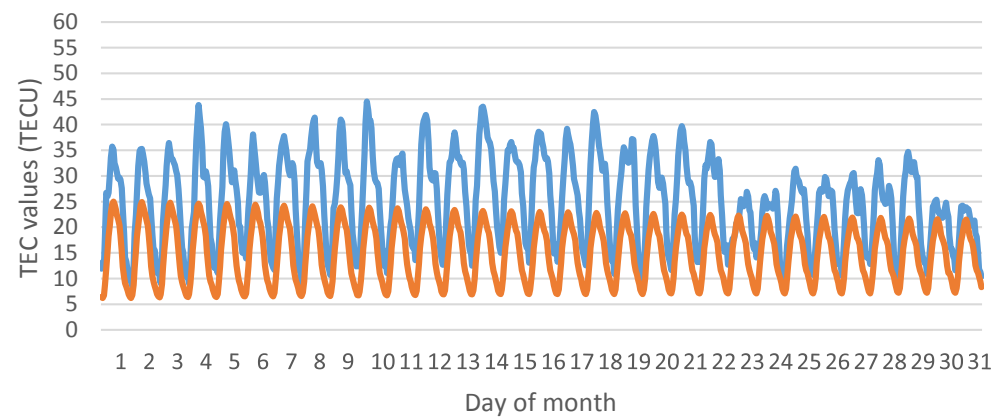

Figure 5. TEC variations in May 2014.
-PPP_TEC

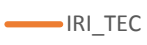

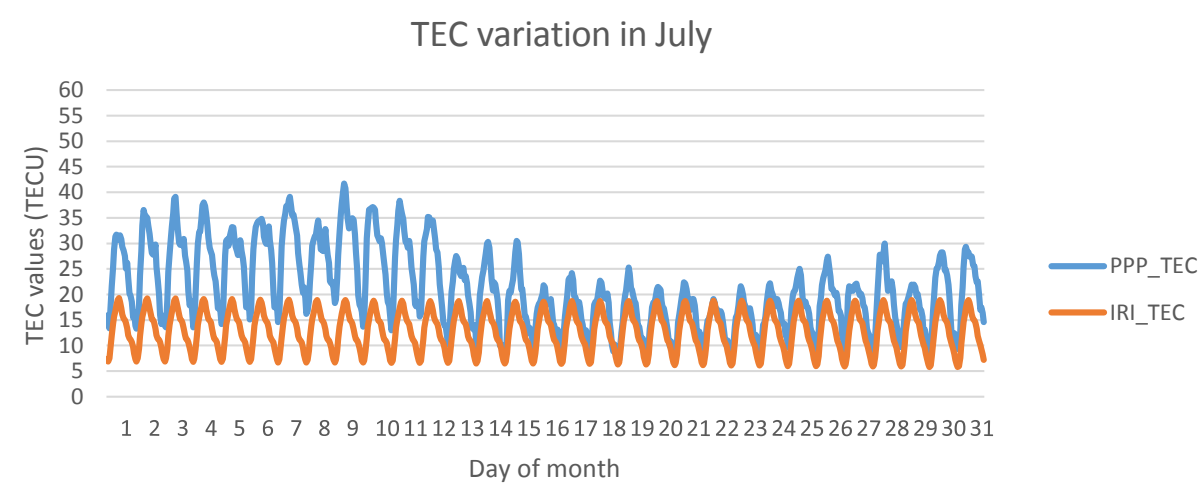

Figure 6. TEC variations in July 2014.

The calibration of the TEC (prediction of the different errors affecting the measurements, such as inter-frequency biases, multipath phase ambiguity, and cycle slips) derived from GNSS code and phase carrier delays should be applied correctly in ionospheric studies (Ciraolo et al., 2007). Calibrated TEC measurements are needed to obtain the spatial variations in TEC and create ionospheric grid maps (Cesaroni et al., 2015). Therefore we have used calibrated TEC values to study seasonal ionospheric variations over the ZONG station.

Generally, TEC values are obtained in various ways. Firstly, we obtain TEC values using only code pseudo-range measurements that provide us with TEC values with an accuracy of 1-5 TECU (Liu et al., 2005). The literature states that code measurements include an element of noise which leads to decreased accuracy in TEC values when compared to phase measurements. Using only code measurements to determine TEC values is therefore not suitable. Another possibility is that TEC values can be achieved by using phase measurements. The accuracy of these TEC values is higher than that obtained from code measurements. However, this method is not suggested to determine correct TEC values because we need to eliminate integer phase initial ambiguities for each GNSS measurement.
The third possible method is that TEC values can be acquired through smoothing code measurements using phase measurements. Thanks to this method, we can both eliminate the obligation of removing the integer phase ambiguity and obtain TEC values easily.

STEC indicates the slant total electron content from satellite to receiver, while VTEC is defined as the vertical total electron content along the ray path in the direction of the zenith:

$\operatorname{STEC}_{a}^{h}=-\frac{f_{1}^{2} f_{2}^{2}}{40.3\left(f_{1}^{2}-f_{2}^{2}\right)}\left(P_{4, a}^{h}-c \mathrm{DCB}_{a}-c \mathrm{DCB}^{h}\right)$.

In this formula, $f_{1}$ and $f_{2}$ indicate GPS frequencies, $\mathrm{c}$ indicates the velocity of light, $P_{4, a}^{h}$ states the differences in $P_{1 \mathrm{smt}, a}^{h}-P_{2 \mathrm{smt}, a}^{h}$ smoothed code measurements, and $\mathrm{DCB}_{a}$ and $\mathrm{DCB}^{h}$ express differential code biases for receiver and satellite respectively (Dach et al., 2011). After obtaining correct STEC values, they are converted to VTEC using a mapping function (MF), which indicates that all electrons are contained in an infinitesimal thickness for each period (Manucci et al., 1993). The altitude of this layer is set at $350 \mathrm{~km}$ for Turkey. Equation (6) describes how to obtain VTEC values using MF:

$\mathrm{VTEC}=\mathrm{STEC} \times \cos \left(\arcsin \left(\frac{R \times \sin z}{R+H}\right)\right)$. 


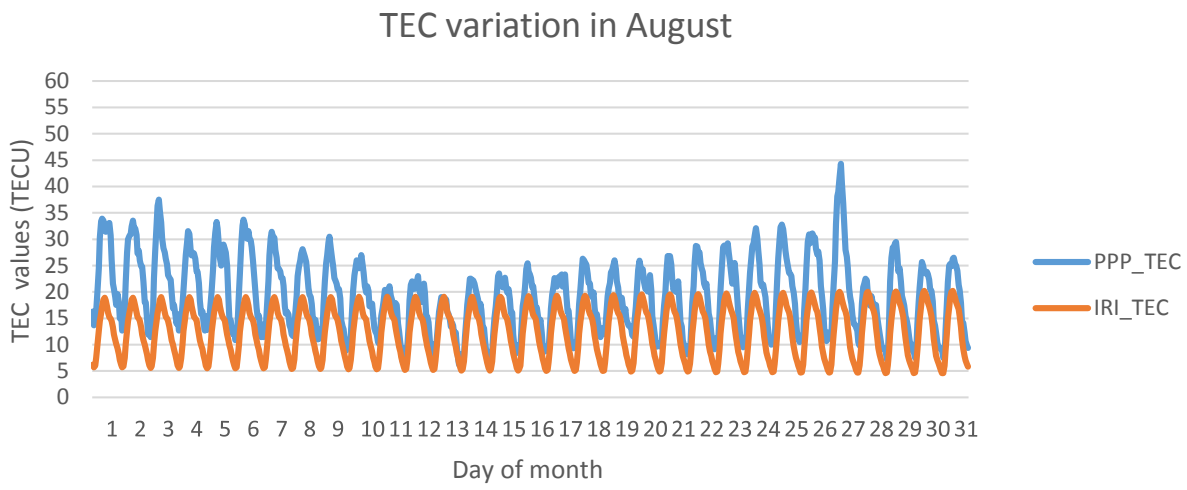

Figure 7. TEC variations in August 2014.

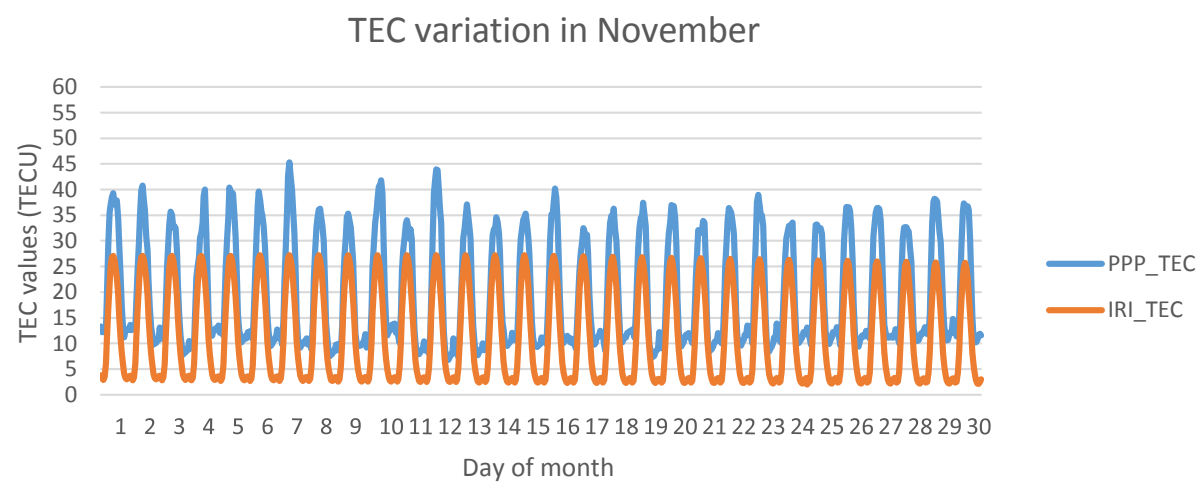

Figure 8. TEC variations in November 2014.

In this formula $R$ expresses the earth's radius, $H$ is the thin shell height of the ionosphere $(350 \mathrm{~km})$, and $z$ is the satellite zenith angle.

\section{Study area and data}

Several studies have been conducted on seasonal variations in the ionosphere over the last few years (Chowdhary et al., 2014; Zakherenkova et al., 2015; Kumar et al., 2014, 2015; Themens and Jayachandran, 2016; Tsai et al., 2001; Wang et al., 2016; Karia et al., 2015; Ssessanga et al., 2015). These studies have concluded that determining the correct VTEC value is important for understanding the behaviour of the ionosphere in terms of seasonal variations. The monitoring of ionospheric variations provides advantages for various disciplines, especially GPS users. In this study, seasonal ionospheric variations were tracked over the western Black Sea at the ZONG station, which is part of a network of continuously operating reference stations in Turkey (CORS-TR). In this respect, a GPS network which includes a total of 41 stations was built. This network includes the International GNSS Service (IGS), the European Reference Frame Permanent Network (EPN), and CORS-TR. All stations used are shown in Fig. 1.
Figure 1 shows the IGS and EPN stations with black labels. These are ANKR, BUCU, CMLD, DUB2, DUTH, GLSV, GRAS, GRAZ, ISTA JOZE, KHAR, KTVL, MATE, MIKL, NICO, NOA1, ORID, PAT0, PENC, POLV, RAMO, SRJV, TUC2, VILL, ZECK, and ZIMM. CORS-TR stations are represented by red labels: AMAS, BOLU, BOYT, CANK, CORU, HEND, INE1, KRBK, KSTM, KURU, NAHA, SAM1, SINP, VEZI, and ZONG. The RINEX data from the IGS and EPN stations were obtained from the URL1, and the RINEX data from the CORS-TR stations were downloaded from the URL-2. IRI-2012 VTEC values are obtained from URL-3. The time interval was $30 \mathrm{~s}$ and the minimum elevation angle was defined as $10^{\circ}$ for processing.

To investigate seasonal ionospheric variation over the ZONG station in Turkey, the International Reference Ionosphere (IRI-2012) model and Bernese 5.2 academic software were used. IRI-2012, which is an international project sponsored by the Committee on Space Research (COSPAR) and the International Union of Radio Science (URSI), is an online tool to obtain VTEC values in desired increments. We selected NeQuick and the $F$ peak model to be defined as URSI input parameters when analysing with the IRI-2012 model. Bernese 5.2 is scientific high-precision data processing software developed at the Astronomical Institute at the University of Bern (AIUB). 


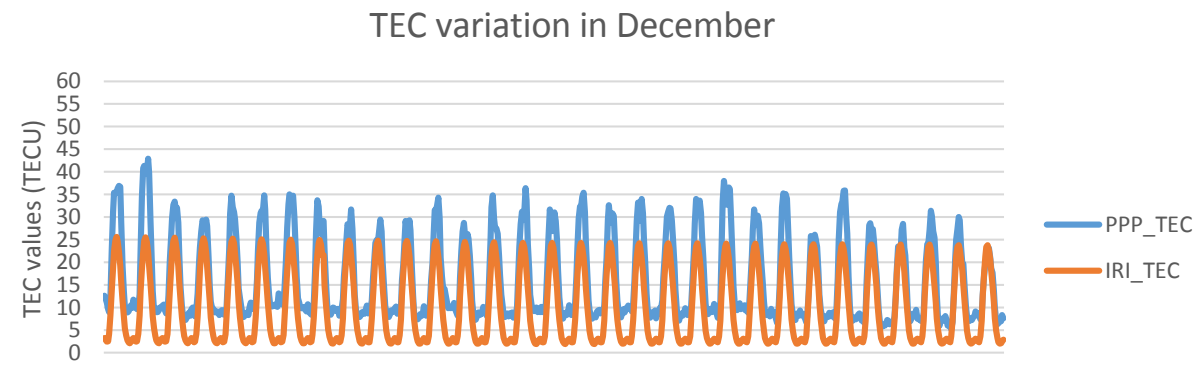

Day of month

Figure 9. TEC variations in December 2014.

Table 1. Statistical results that produced PPP_TEC.

\begin{tabular}{lrrrr}
\hline Months & $\begin{array}{r}\text { Min. TEC } \\
\text { (TECU) }\end{array}$ & $\begin{array}{r}\text { Max. TEC } \\
(\text { TECU) }\end{array}$ & $\begin{array}{r}\text { Mean TEC } \\
\text { (TECU) }\end{array}$ & $\begin{array}{r}\text { Standard deviation } \\
\text { (TECU) }\end{array}$ \\
\hline Jan & 5.5 & 31.3 & 13.35 & 6.41 \\
Feb & 4.9 & 53.7 & 20.90 & 11.73 \\
Apr & 9.0 & 59.8 & 29.73 & 12.52 \\
May & 8.5 & 44.5 & 24.98 & 8.67 \\
Jul & 7.2 & 41.7 & 21.09 & 7.84 \\
Aug & 6.2 & 44.3 & 19.23 & 7.07 \\
Nov & 6.8 & 45.3 & 19.52 & 10.67 \\
Dec & 5.2 & 42.9 & 16.11 & 9.4 \\
\hline
\end{tabular}

\section{Results}

In this study, attempts were made to monitor ionospheric conditions in terms of seasonal variations. Therefore 2month RINEX data from the ZONG station for each season were processed to analyse ionospheric variations over the western Black Sea in Turkey. All the results are shown in Figs. 2 to 9. The blue labels indicate the PPP_TEC results that were produced using Bernese 5.2, while the red labels explain the results for IRI_TEC that were obtained using IRI2012.

When all figures are examined, it can be clearly seen that the IRI-TEC values produced nearly the same response in terms of monthly ionospheric activity. For example, the maximum TEC value is nearly 25 TECU for each day in December 2014. However, GPS_TEC gives different responses for these days. On the other hand, IRI-2012 nearly underestimated the values for every month when compared to the GPS_TEC values. The changes in the obtained TEC values from IRI-2012 and Bernese 5.2 were statistically analysed for each month to monitor seasonal variations over the ZONG station in Turkey. The results obtained are shown separately in Tables 1 and 2.

In the current research, while the maximum TEC value was seen in April 2014, the minimum TEC value was produced in February 2014 according to the PPP_TEC results. When the IRI_TEC values are examined, it is clearly understood that the maximum TEC value was obtained in
Table 2. Statistical results that produced IRI_TEC.

\begin{tabular}{lrrrr}
\hline Months & $\begin{array}{r}\text { Min. TEC } \\
\text { (TECU) }\end{array}$ & $\begin{array}{r}\text { Max. TEC } \\
(\text { TECU) }\end{array}$ & $\begin{array}{r}\text { Mean TEC } \\
(\text { TECU) }\end{array}$ & $\begin{array}{r}\text { Standard deviation } \\
\text { (TECU) }\end{array}$ \\
\hline Jan & 2.0 & 23.4 & 9.11 & 7.64 \\
Feb & 1.0 & 26.1 & 11.37 & 8.56 \\
Apr & 4.6 & 27.2 & 15.24 & 7.91 \\
May & 6.2 & 25.0 & 14.99 & 5.6 \\
Jul & 5.8 & 19.3 & 12.83 & 3.87 \\
Aug & 4.6 & 20.2 & 12.39 & 4.79 \\
Nov & 2.0 & 27.1 & 11.48 & 9.1 \\
Dec & 1.9 & 25.6 & 9.9 & 8.23 \\
\hline
\end{tabular}

April 2014, while the minimum TEC value was achieved in February 2014. When the mean TEC values are examined, the highest mean TEC value was seen in April 2014 for both PPP_TEC and IRI_TEC, and the lowest mean TEC value was presented in January 2014 for both models. The standard deviation reached a peak value in April 2014 and the lowest value in January 2014 according to the PPP-TEC results. When the IRI_TEC results are examined, it is understood that the maximum standard deviation was seen in April 2014, while the minimum standard deviation was observed in July 2014. It is well understood that the ionosphere has a dependence on seasonal variations. Therefore, seasonal ionospheric effects should be taken into account in all signalbased studies.

\section{Conclusions}

The ionosphere can be monitored using a variety of instruments, such as ionosondes, incoherent scatter radar, topside sounders, and onboard satellites. Since these instruments are expensive and extract limited information about the ionosphere, GPS has become an optimal way to examine ionospheric behaviour.

Many researchers have demonstrated that the ionosphere is affected by seasonal variations and that such effects have been shown in terms of GPS measurements. In this study, seasonal ionospheric variations over Turkey from the ZONG 
station were implemented using GPS-based TEC and IRI2012. When the results are examined for the two models, we obtained different TEC values for each season. Furthermore, the IRI-2012 results were compared with the GPS results, and it is clear that IRI-2012 underestimates the TEC values for each month analysed. On the other hand, we know that the IG12 ionospheric index and the Rz12 sunspot index generate only 1 value per month and that they are interpolated by the model. The model was not intended to track day-today variations accurately. Therefore the IRI-2012 results produce nearly the same TEC values at any time of day within the month. When the ionosphere is considered as a dynamic layer, the IRI-2012 results do not represent real ionospheric conditions. Therefore we conclude that IRI-2012 does not provide a sufficiently accurate daily ionospheric activity response. The main reason for TEC differences may stem from the absence of a correct representation of the plasmaspheric part of the ionosphere. While IRI-2012 produces VTEC as a result of the integration of the electron density profile within altitudinal limits of $60-2000 \mathrm{~km}$, GPS is set to $20200 \mathrm{~km}$ from the ground. We conclude from this study that the plasmaspheric part of the ionosphere should be correctly taken into account in monitoring the ionosphere.

Data availability. The RINEX data from the IGS and EPN stations were obtained from URL 1, and the RINEX data from the CORSTR stations were downloaded from URL 2. IRI-2012 VTEC values are obtained from URL 3 . The URLs are as follows: URL 1: ftp://igs.bkg.bund.de/IGS/obs/, 2014. URL 2: http://212.156.70.42/, 2014. URL 3: https://omniweb.gsfc.nasa.gov/vitmo/iri2012_vitmo. html.

Competing interests. The authors declare that they have no conflict of interest.

Acknowledgements. We are grateful to the International GNSS Service (IGS) and EPN (EUREF Permanent Network) for providing RINEX data and other products. The authors would also like to thank the editor, Ioannis A. Daglis, and the referees for their valuable comments and suggestions for improving the quality of the paper.

The topical editor, Steve Milan, thanks David Siddle and three anonymous referees for help in evaluating this paper.

\section{References}

Chakraborty, M., Kumar, S., De, B. K., and Guha, A.: Latitudinal characteristics of GPS derived ionospheric TEC: a comparative study with IRI 2012 model, Ann. Geophys., 57, A0539, https://doi.org/10.4401/ag-6438, 2014.

Chowdhary, R. V., Tripathi, N. K., Arunpold, S., and Raju, D. K.: Variations of total electron content in the equatorial anomaly region in Thailand, Adv. Space Res., 55 231-242, 2015.
Ciraolo, L., Azpilicueta, F., Brunini, C., Meza, A., and Radicella, S. M.: Calibration errors on experimental slant total electron content (TEC) determined with GPS, J. Geodesy., 81, 111-120, 2007.

Cesaroni, C., Spogli, L., Alfonsi, L., De Franceschi, G., Ciraolo, L., Monico, J. F. G., and Bougard, B.: L-band scintillations and calibrated total electron content gradients over Brazil during the last solar maximum, Journal of Space Weather and Space Climate, 5, A36, 1-11, 2015.

Coley, W. R., Stoneback, R. A., Heelis, R. A., and Hairston, M. R.: Topside equatorial zonal ion velocities measured by C/NOFS during rising solar activity, Ann. Geophys., 32, 69-75, https://doi.org/10.5194/angeo-32-69-2014, 2014.

Dach, R., Hugentobler, U., and Walser, P.: Bernese GPS Software (Version 5.0), Astronomical20 Institute, University of Bern, Bern, Switzerland, 2011.

Karia, S. P., Patel, N. C., and Pathak, K. N.: Comparison of GPS based TEC measurements with the IRI-2012 model for the period of low to moderate solar activity (2009-2012) at the crest of equatorial anomaly in Indian region, Adv. Space Res., 55, 19651975, 2015.

Kumar, S., Tan, E. L., Razul, S. G., See, C. M. S., and Siingh, D.: Validation of the IRI-2012 model with GPS-based ground observation over a low-latitude Singapore station, Earth Planet. Space, 66, 1-10, 2014.

Kumar, S., Tan, E. L., and Murti, D. S.: Impacts of solar activity on performance of the IRI-2012 model predictions from low to mid latitudes, Earth Planet. Space, 67, 1-17, 2015.

Liu, Z., Gao, Y., and Skone, S.: A Study Of Smoothed TEC Precision Inferred From GPS, Earth Planet. Space, 57, 999-1007, 2005.

Mannucci, A. J., Wilson, B. D., and Edwards, C. D.: A new method for monitoring the Earth's ionospheric total electron content using the GPS global network, 1993.

Mannucci, A. J., Wilson, B. D., Yuan, D. N., Ho, C. H., Lindqwister, U. J., and Runge, T. F.: A global mapping technique for GPSderived ionospheric total electron content measurements, Radio Sci., 33, 565-582, 1998.

Otsuka, Y., Ogawa, T., Saito, A., Tsugawa, T., Fukao, S., and Miyazaki, S.: A new technique for mapping of total electron content using GPS network in Japan, Earth Planet. Space, 54, 63-70, 2002.

Petrie, E. J., Hernandes-Pajares, M., Spalla, P., Moore, P., and King, M. A.: A Review of Higher Order Ionospheric Refraction Effects on Dual Frequency GPS, Surv. Geophys., 32, 197-253, 2011.

Rama Rao, P. V. S., Niranjan, K., Prasad, D. S. V. V. D., Gopi Krishna, S., and Uma, G.: On the validity of the ionospheric pierce point (IPP) altitude of $350 \mathrm{~km}$ in the Indian equatorial and low-latitude sector, Ann. Geophys., 24, 2159-2168, https://doi.org/10.5194/angeo-24-2159-2006, 2006.

Schmidt, M., Bilitza, D., Shum, C. K., and Zeilhofer, C.: Regional 4-D modeling of the ionospheric electron density, Adv. Space Res., 42, 782-790, 2008.

Spogli, L., Alfonsi, L., Cilliers, P. J., Correia, E., De Franceschi, G., Mitchell, C. N., and Cabrera, M. A.: GPS scintillations and total electron content climatology in the southern low, middle and high latitude regions, Ann. Geophys., 56, R0220, https://doi.org/10.4401/ag-6240, 2013. 
Ssessanga, N., Kim, Y. H., Kim, E., and Kim, J.: Regional optimization of the IRI-2012 output (TEC, foF2) by using derived GPS-TEC, J. Korean Phys. Soc., 66, 1599-1610, 2015.

Themens, D. R. and Jayachandran, P. T.: Solar activity variability in the IRI at high latitudes: Comparisons with GPS total electron content, J. Geophys. Res.-Space, 121, 3793-3807, 2016.

Tsai, H. F., Liu, J. Y., Tsai, W. H., Liu, C. H., Tseng, C. L., and $\mathrm{Wu}, \mathrm{C}$. C.: Seasonal variations of the ionospheric total electron content in Asian equatorial anomaly regions, J. Geophys. Res.Space, 106, 30363-30369, 2001.
Wang, C., Shi, C., Zhang, H., and Fan, L.: Improvement of global ionospheric VTEC maps using the IRI 2012 ionospheric empirical model, J. Atmos. Sol.-Terr. Phys., 146, 186-193, 2016.

Yildirim, O., Inyurt, S., and Mekik, C.: Review of variations in $\mathrm{Mw}<7$ earthquake motions on position and TEC $(\mathrm{Mw}=6.5$ Aegean Sea earthquake sample), Nat. Hazards Earth Syst. Sci., 16, 543-557, https://doi.org/10.5194/nhess-16-543-2016, 2016.

Zakherenkova, I. E., Cherniak, I. V., Krankowski, A., and Shagimuratov, I. I.: Vertical TEC representation by IRI 2012 and IRI Plas models for European midlatitudes, Adv. Space Res., 55, 2070 2076, 2015. 